\title{
Dimensions of Technological Developments across Different Phases of the Product Life Cycle - An Explorative Study in the Indian Machine Building Sector
}

\author{
Avvari V. Mohan and \\ K.N.Krishnaswamy \\ Department of Management \\ Indian Institute of Science, \\ Bangalore - 560 012. India
}

\author{
Kim Ji Soo \\ Director: Techno-Management Program \\ Korea Advanced Institute of Science and Technology \\ 207-43, Cheongyangri-dong, Dongdaemoon-gu, \\ Seoul 130-012, Korea
}

\begin{abstract}
This paper reports the findings of survey, aimed at understanding the dimensions of technological developments (TDs) in different phases of the Product Life Cycle (PLC). The study is based on a survey done in a sample of Indian machinery manufacturing organisations in the context of the economic liberalisation in India which has allowed free imports of technology and goods. This has brought about a greater need for continuous TDs to obtain sustainable competitive benefits throughout the PLC. Various dimensions of TDs were obtained through a factor analysis and the results suggested the relative importance of the dimensions of TDs varied according to the phase of the PLC.
\end{abstract}

\section{INTRODUCION}

The process of economic liberalisation in India has allowed free imports of technology and goods which has led to intense competition and shorter Product Life Cycles (PLC). In such conditions to serve the market needs of lower costs and higher quality, technological developments related to product and process improvements become crucial in any manufacturing organisation. The need for continuous TDs, sometimes also known as incremental innovations, both product and process related, is being felt by the marketers in Indian industrial goods organisations in order to obtain sustainable competitive benefits through out the life cycle of the product. A review of literature reveals that there are research studies which propose that TDs should be different across the life cycle, matching business strategies. But it appears that there are no comprehensive studies relating TDs at the product level, across different phases of the life cycle.

To enable an organisation to control the growth of its products through their life cycle, each phase of the PLC calls for different patterns of management, particularly of technology involving appropriate changes in the efforts towards product oriented TDs (Utterback \& Abernathy 1975, Frohman 1982, Frohman \& Bitondo 1991).

Most studies of the process of TDs under technological innovations have concentrated on activities that have resulted in commercial introduction of new products and processes. The process of technological innovation at this stage was considered to be complete (Rothwell \& Gardiner 1989). But even after a product is launched into the market it undergoes changes. These changes, which could be product and/or process related TDs in the post-launch phase of the product, are expected to be influenced by the product's marketing programme (Kiel 1992). Also known as Incremental innovations, these TDs are those changes involving the continuous stream of innumerable minor adjustments, modifications and adaptations. Incremental or continuous TDs are particularly important in developing countries, which are clearly not technological innovators (Lall 1995), as they allow a manufacturing firm to transform itself from being a technology follower to a technology leader (Chandra and Shukla 1994). Except with a few notable exceptions (Rothwell \& Gardinar,1989), empirical studies on TDs in the post-launch phases of a product have been fragmented.

The above discussion related to TDs leads to reasonably believe that there may be a unique set of dimensions of TDS in the different phases of the PLC for products already in the market. Also the question that needs to be answered is are the same set of variables of technological developments relevant in all PLC phases and are the dimensions same or different for the phases? Thus such a study attempted here is warranted to understand the dimensions of technological developments across PLC phases. This would be useful in matching programs for technology developments to the needs of marketing in an organisation, particularly in the context of economic liberalisation in India.

The study is an exploratory one, conducted in a sample of 63 Indian organisations manufacturing general purpose machinery. To achieve the objectives a cross sectional design was adopted to conduct the study. Ten product related technological development variables were identified from literature and listed in the four PLC phases. A questionnaire was developed using these variables. All the variables were measured using Likert type 5-point bi-polar scales. Data pertaining to a total of 191 product lines in four PLC phases (42 in the introduction phase, 59 in the growth, 53 in the maturity and 39 in the decline phase) was collected through face-to-face interviews using the specially developed questionnaire. 


\section{RESULTS OF THE STUDY: DIMENSIONS OF TECHNOLOGICAL DEVELOPMENTS ACROSS THE PLC}

The analysis and results presented in this section relate to the identification of the underlying dimensions of technological developments (TDs) in each phase of the PLC. For each phase of the PLC, factor analysis was performed on the data obtained for the ten product related TD variables and the factors obtained are presented. Using the eigen value of one as criterion and principal components analysis, factor solutions were derived at each phase of PLC. The factor analysis was done using the SPSS PC + package.

\section{A. Introduction Phase}

Factor analysis was carried out on a sample of forty two products in this phase. A four (4) factor solution was obtained. They accounted for $69.1 \%$ of the total variance. Table 1 presents the factors extracted after the varimax rotation. Factor 1 loads heavily (more than 0.5 ) on variables quality, reliability and feature related product oriented TDs. It is called 'Quality' factor and explains $25.2 \%$ of the variance.

TABLE 1

INTRODUCTION PHASE - FACTORS OF PRODUCT ORIENTED TECHNOLOGICAL DEVELOPMENTS

\begin{tabular}{|c|c|c|c|c|}
\hline C. & Pर $106 \%$ & 19206\% 2 & $171060 \%$ & 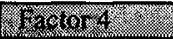 \\
\hline $301010,5.8=$ & oundr: & Yor.want & Anuenturive & 2010101 \\
\hline Feature & .7762 & & & \\
\hline Quality & .7628 & & & \\
\hline Reliability & .6289 & & & \\
\hline Scale Variants & & .8848 & & \\
\hline Range of Use & & .7678 & & \\
\hline Modifications & & .6713 & & \\
\hline $\begin{array}{l}\text { Appearance } \\
\text { Dimensions }\end{array}$ & & & $\begin{array}{l}.8445 \\
.6204\end{array}$ & \\
\hline $\begin{array}{l}\text { Material } \\
\text { Function }\end{array}$ & & & & $\begin{array}{l}.8636 \\
.6215\end{array}$ \\
\hline 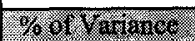 & 25.2 & 1793 & $13.5=$ & 13,3 \\
\hline Eigen Value & 2.515 & 1.734 & 1.350 & 1.330 \\
\hline
\end{tabular}

Factor 2 emphasises TDs related to variants in the product. The variables with high factor loading in this case are, variants, range of use and modifications of the products. This factor explains around $17 \%$ of the variance and is named as 'Variants'.

The third factor loads heavily on variables concerning appearance and dimensions. This factor is called 'Appearance' factor and explains around 13\% of the variance. The fourth factor also explaining $13 \%$ of the variance had material and function related TDs highly loaded on to it. This factor is named 'Material' .

\section{B.Growth Phase}

In this phase factor analysis was carried out on a sample fifty nine (59) products. A two factor solution was obtained. These two factors accounted for $60.9 \%$ of the total variance. Table 2 presents the factors extracted after the varimax rotation.

TABLE 2

GROWTH PHASE - FACTORS OF PRODUCT ORIENTED TECHNOLOGICAL DEVELOPMENTS

\begin{tabular}{|c|c|c|}
\hline Grinure & 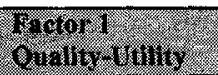 & peror 1 \\
\hline Reliability & .9017 & \\
\hline Function & .8452 & \\
\hline Features & .8999 & \\
\hline Quality & .6085 & \\
\hline Materials & .5760 & \\
\hline Appearance & & .8031 \\
\hline Scale Variants & & .8014 \\
\hline Modifications & & .7299 \\
\hline Range of use & & .6375 \\
\hline Dimensions & & .5095 \\
\hline 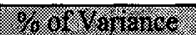 & $477 \%$ & $1931=$ \\
\hline Eigen Value & 4.168 & 1.925 \\
\hline
\end{tabular}

The factor I comprises of the following five variables, materials, function, features, quality and reliability. This factor alone accounts for $41.7 \%$ of the total variance. This factor is named as 'Quality-Utility' factor. The variables loaded on it provide a combination of quality and utility. The highest loading of .9017 on this factor is of reliability and then features with 0.899 followed by function with 0.845 as loadings

The 2nd factor comprised of five variables and accounted for $19.3 \%$ of the variance. This factor loads heavily of variables comprising of dimensions, appearance, range-ofuse, modifications and scale variants. appearance and scale variants have high loadings of 0.803 and 0.802 respectively. This factor has been named as 'Variant' factor.

In this phase, it can be seen that there is a sharp drop in the Eigen value between the factor I and factor II (41.7 to 19.3). This can be thought of as an indication of the relative importance of Quality dimension over the other dimension.

\section{Maturity Phase}

In this phase factor analysis was carried out on a sample of fifty three products and a four (4) factor solution was obtained. They accounted for $82.9 \%$ of the total variance. The four factors had Eigen values of 4.46, 1.62, 1.13 and 1.06 indicating the relative importance of the factors in accounting for the variance in this phase. Table 3 presents the factors derived after the varimax rotation, their Eigen values, loading and the names.

The I factor loads heavily of variables concerned with product modifications, range-of-use, scale variants and appearance. This factor alone accounted for $44.6 \%$ of the 
variance in this variable set. It is named as 'Variants' factor. This indicates the importance of TDs towards developing variations of products in this phase where entering new markets, re-launching old products has been emphasised by executives interviewed.

The second factor which accounted for $16.3 \%$ of the variance in the total variable set had, product features and function related TD variables loaded on to it. This factor is named 'Utility'. The third factor comprised of the variables quality and reliability. This factor accounts for $11.4 \%$ of the total variance and named as 'Quality' factor. The difference in the Eigen values of II and III factor when compared with the I factor could indicate their relative importance in this phase.

TABLE 3

MATURITY PHASE - FACTORS OF PRODUCT ORIENTED TECHNOLOGICAL DEVELOPMENTS

\begin{tabular}{|c|c|c|c|c|}
\hline & Factor 1 & Factor 2 & Factor 3 & Factor 4 \\
\hline Tarroles & Varthentin & Whitity & ourany & Matemas \\
\hline Range of Use & .9506 & & & \\
\hline Modifications & .9023 & & & \\
\hline Appearance & .9012 & & & \\
\hline Scale Variants & .8528 & & & \\
\hline Features & & .8870 & & \\
\hline Function & & .7143 & & \\
\hline Reliability & & & .9028 & \\
\hline Quality & & & .8044 & \\
\hline Materials & & & & .8785 \\
\hline Dimensions & & & & .7094 \\
\hline of of Vortintec & 446 & 16.3 & 11.4 & 10.6 \\
\hline Eigen Value & 4.46 & 1.62 & 1.13 & 1.06 \\
\hline
\end{tabular}

The fourth factor is loaded with the material and dimensions related TD variables. This could indicate that in this phase the changes in dimensions of the product involve changes in material or using new materials. This factor is named 'Material factor.

\section{Decline Phase}

In the decline phase, factor analysis was carried out on a sample of thirty nine (39) products. Like in the Introduction and Maturity phases, in this phase also 4 factors related to product oriented TDs were extracted using the factor analysis.

The 4 product oriented TD factors together account for 65.7 $\%$ of the variance. These four factors had Eigen values of 2.96, $2.32,1.29 \& 1.03$ indicating the relative importance in accounting for the variance in this set of variables. Table 4 presents the factors derived after the variance rotation, their Eigen values, loadings and their names.

The I factor loads heavily on variables concerned with feature changes and scale variants. This factor alone accounted for $29.6 \%$ of the variance in this variable set. It is named as 'Variants' factor. This indicates the importance of TD towards developing variations of products in this phase where re-launching of old products was emphasised by the executives interviewed.

TABLE 4

DECLINE PHASE - FACTORS OF PRODUCT ORIENTED TECHNOLOGICAL DEVELOPMENTS

\begin{tabular}{|c|c|c|c|c|}
\hline & Factor 1 & Factor 2 & Factor 3 & Factor 4 \\
\hline Yartables & Vratantits & Couns: & Uth: & आar) \\
\hline Features & .9056 & & & \\
\hline Scale Variants & .8520 & & & \\
\hline Appearance & & .7954 & & \\
\hline Reliability & & -.7690 & & \\
\hline Dimensions & & .6637 & & \\
\hline Quality & & -.6404 & & \\
\hline Range of Use & & & .8440 & \\
\hline Modifications & & & .7681 & \\
\hline Material & & & & .8489 \\
\hline Function & & & & .6445 \\
\hline 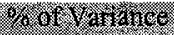 & 29.1. & 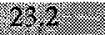 & & 10.2 \\
\hline Eigen Value & 2.96 & 2.32 & 1.29 & 1.03 \\
\hline
\end{tabular}

The second factor which accounted for $23.2 \%$ of the variance in the total variable set has product appearance, reliability, dimensions and quality related variables loaded on to it. This factor is named 'Quality'.

The third factor comprised of the variables range of use and modifications. This factor accounts for $12.9 \%$ of the total variance and named as 'Utility' factor. The difference in the Eigen values of II and III factor when compared with the I factor indicates the relative importance in this phase.

The fourth factor is loaded with material and function related TD variables. In this phase as re-tailoring products to give them a new lease of life has also emphasised, this could involve making changes in a product's function or in the materials for some benefit. This factor is named 'Material' factor.

\section{SUMMARY AND CONCLUSIONS}

In terms of theory, the results of factor analysis are useful in supporting the view that dimensions of TDs will be different depending on the phase of PLC. From the factor analyses the product related dimensions obtained are Product Quality, Product Variants, Product Utility, Product Appearance and Product Materials. The relative importance of the TD dimensions in each PLC phase are deduced form the relevant factor loading tables.

\section{A.. Some important inferences}

(i) In the Introduction phase the 'Quality' dimension was most important while in the Growth phase it was the 'Utility' dimension that was the most important. In the Maturity phase the 'Variant' dimension was most important while in the Decline phase it was 'Variants and Appearance' related dimensions. 
(ii) Though the names have been suggested based on the factor loadings, these dimensions are sometimes composed of different variables. Variables have jumped factors, for eg., the 'Variants' factor in the Introduction phase which was composed of TDs oriented towards, range of use, modifications and scale variants, in Growth phase, had in addition variables related to dimension and appearance in it.

(iii) The factor 'Material' is the least important in all phases except in the Growth phase, where material substitutions are effected in most imported technologies. Usually by this phase in the PLC the organisaton will have completely adopted the imported technology and starts going in for adaptations like substituting locally available materials instead of imported ones or in somecases to suit some specific local need.

(iv) Dimensions of 'Quality' and 'Reliability' which are in the first position of importance in the former phases are relegated to a lower position in the later two phases of the PLC.

(v) TD dimension 'Variants', appears to be a critical factor for Indian machinery manufacturing companies, as it never occupies lower than the second position of importance. This indicates the vital importance of introducing product changes through TD efforts, by the in-house technology function.

The present study has been an attempt to understand the dimensions of technological developments (TDs) across different phases of the product life cycle. From the results, it is evident that TD dimensions are different in different phases of the PLC. From the point of view of business strategy, for organisations where technology is the life blood, the results of the study are helpful in avoiding allocation of resources in a sub-optimal fashion, particularly in the technology function, and in aiming at synergetic planning for technology to achieve overall business goals.

The study has been done with specific reference to the Indian machinery manufacturing sector. The patterns observed in this sector need not necessarily prevail in other sectors. More research endeavors in other industrial sectors would be useful to determine the difference in patterns of TDs. This would also be useful in generalising the findings.

\section{REFERENCES}

Chandra, P. and Shukla, P.R., "Manufacturing Excellence and Global Competitiveness - Challenges and Opportunities for Indian Industries," Economic and Political Weekly, Feb. 26, 1994.

Frohman, A.L., "Technology as a Competitive Weapon," Harvard Business Review, Jan.-Feb. 1982. pp 97-100.

Frohman, A.L., "Putting Technology to Strategy," Journal of Business Strategy, No 5, 1985. pp.54-65

Frohman, A.L. and Bitondo, D., "Coordinating Business Strategy and Technology Planning," Long Range Planning, Vol 14, No. 6, 1991. pp.5867.

Kiel, Geoffrey, "Technology and Marketing, the Magic Mix," in Timpe, D.A. (Ed). The Art and Science of Business Management - Marketing (Vol. VII), New Delhi: Jaico Publishing House, 1992.

Lall, S., "Policies for Building Technological Capabilities: Lessons from Asian Experience," Asian Development Review, 1995. pp.72-103.

Rothwell R. and Gardiner, P., "The Strategic Management of Reinnovation," R\&D Management, Vol. 19, No. 2, 1989. pp.147-160.

Utterbaack, J.M. and Abernathy, W.J., "A dynamic Model of Process and Product Innovation," Omega, The International Journal of Management Science, Vol. 3, No. 2, Oct 1975. pp. 639-656. 